\title{
Evaluation of selected transgenic papaya (Carica papaya L.) lines for inheritance of resistance to papaya ringspot virus and horticultural traits
}

\author{
Abigail May O. Retuta', Pablito M. Magdalita², Evalour T. Aspuria2,*, \\ Rene Rafael C. Espino ${ }^{2}$ \\ ${ }^{1}$ Philippine Council for Agriculture, Aquatic, Forestry and Natural Resources Research and Development (PCAARRD), \\ 4030 Los Baños, Laguna, Philippines; ${ }^{2}$ Crop Science Cluster, College of Agriculture, University of the Philippines Los Baños \\ (UPLB), 4031 College, Laguna, Philippines \\ *E-mail: etaspuria@yahoo.com Tel: +63-49-536-2468 Fax: +63-49-536-5287
}

Received December 5, 2011; accepted February 15, 2012 (Edited by G.-T. Kim)

\begin{abstract}
Three selected transgenic papaya lines 124-3, 132-2 and 142-3 across the $\mathrm{T}_{1}$ and $\mathrm{T}_{2}$ generations were preliminarily evaluated under Biological Containment Level 2 (BL2) greenhouse approved by the National Committee on Biosafety of the Philippines (NCBP) to determine the partial stability of expression of resistance to papaya ringspot virus (PRSV) and selected phenotypic traits. The PRSV reaction of the three transgenic lines using mechanical inoculation test and enzyme-linked immunosorbent assay was assessed. The qualitative and quantitative horticultural traits at flowering and ripe fruit stages of the transgenic lines were also evaluated. Based from preliminary results, the percentages of resistant progenies to PRSV in the $\mathrm{T}_{1}$ generation were $83 \%$ for $124-3,74 \%$ for $132-2$, and $70 \%$ for $142-3$. However, in the same generation, no difference between the transgenic and non-transgenic were observed for stem, leaf and petiole color, fruit shape, peel, flesh and seed color, stem diameter, number of days to first flower, and fruit edible portion, indicating that the transgenic is seemingly stable. The percentage of resistant progenies to PRSV in the $\mathrm{T}_{1}$ generation decreased in the $\mathrm{T}_{2}$ generation, indicating that the inherited resistance of the three transgenic lines was unstable, and a continuous evaluation of the transgene could be done in later generations. In contrast, the light green (RHS 141B) stem color, dark green (RHS 141A) leaves and petioles and creamy white flowers (RHS 155A) were stably expressed in both the $\mathrm{T}_{1}$ and $\mathrm{T}_{2}$ generations. The plant height for lines 124-3 and 142-3, internode length for line 142-3 and number of nodes to first flower for lines 132-2 and 142-3 were also stable in both $\mathrm{T}_{1}$ and $\mathrm{T}_{2}$ generations. In addition, the pyriform fruit shape for hermaphrodite sex form and rounded fruit shape for the female sex form, light yellow orange (RHS 17A) peel color, bright yellow orange (RHS 23A) flesh color and black (RHS 202A) seeds of the three transgenic lines were stably expressed in both generations. The fruit weight, total soluble solids and fruit edible portion for lines 124-3 and 142-3 was stably expressed in both generations.
\end{abstract}

Key words: Carica papaya L., coat protein gene, horticultural traits, inheritance, papaya ringspot virus, resistance, enzyme-linked immunosorbent assay

The papaya (Carica papaya L.), a member of the family Caricaceae is a single-stemmed semi-woody herbaceous plant which is widely grown in tropical and subtropical regions of the world. The melon-like fruits are edible and highly nutritious because they are rich in vitamins, minerals and fiber. Its flesh when ripe may be golden yellow like 'Kapoho', and 'Waimanalo' Solo and 'Cavite Special' or red like 'Sunrise' and 'Sunset' Solo and 'Red Lady'. The unripe fruits are rich sources of papain, an enzyme used as a component of meat tenderizers and also used the in the manufacture of pharmaceutical and cosmetic products.

Papaya plantations often range from small to largescale commercial farms. The area planted to papaya in the Philippines is 9,280 ha with a production volume of
182,908 metric tons (DA-BAS, 2009). The production of papaya especially in the Southern Tagalog region is a lucrative business until the outbreak of the deadly papaya ringspot virus (PRSV) that devastated the papaya industry in this region. The disease has been spreading like a wild-fire because it is being transmitted by aphids in a non-persistent manner (Magdalita et al. 1989). The virus can infect papaya plants at any stage of growth. To date, there is no known ultimate solution for this disease. However, conventional breeding efforts led to the development of moderately tolerant varieties like the 'Sinta' hybrid. Intergeneric hybridization between papaya and its wild relatives produced hybrids but hybrid breakdown prevented further backcrossing to recover a resistant variety (Magdalita et al. 1996, 1997). Hence, the 
use of genetic engineering to develop resistance offers an alternative solution to solve the problem.

In agriculture, genetic engineering is utilized mostly for the development of resistant crops to pests and diseases, tolerance to abiotic stresses and in the elucidation of gene functions and gene products via plant transformation. The most effective method of controlling plant viruses is through building up resistance (Fuchs and Gonsalves 2007). For instance, the PRSV-resistant Hawaiian transgenic papaya variety 'SunUp' was developed through transformation of somatic embryos with the coat protein gene of the Hawaiian PRSV mutated strain (Fitch et al. 1992). The transgenic plants are therefore protected from the infecting virulent Hawaiian PRSV strain only.

In the development of transgenic crops resistant to viruses, it is important to assess fully the resistance and its inheritance pattern. In addition, the phenotypic characteristics need to be tested whether they are similar to the non-transgenic counterpart, which is important for regulatory purposes and variety release. In other transgenic crops agronomic traits and yield performance has been evaluated for instance, in transgenic squash that contained single or multiple virus coat protein gene (Tricoli et al. 1995), burley tobacco that expresses tobacco vein mottling virus or alfalfa mosaic virus coat protein genes (Xu et al. 1999), peanut resistant to tomato spotted wilt virus (Yang and Ozias-Akins 2004), tomato hybrids resistant to tomato spotted wilt virus (Accotto et al. 2005) and papaya resistant to papaya ringspot virus Hawaiian isolate (Bau et al. 2004; Ferreira et al. 2002; Phironrit et al. 2007; Tennant et al. 2005). There were either no or few differences in agronomic traits of the transgenic crops in comparison to their non-transgenic counterparts. In most cases, the transgenic crops had better yield performance than their non-transgenic counterparts.

Finally, the test for a successful plant transformation especially for resistance to viral pathogens is an assessment of the stability of incorporated transgenes through characterization of resistance from one generation to the next. Hence, the main objective of this study is to: i) assess the resistance to PRSV of the selected transgenic lines and stability of resistance trait across two generations and, ii) evaluate the selected horticultural traits of the three transgenic lines in $\mathrm{T}_{1}$ and $\mathrm{T}_{2}$ generations.

\section{Materials and methods}

The materials used in this study were obtained from a project, "Development and Commercialization of GM Papaya for Fresh Fruit and Papain Production", under the leadership of Dr. Pablito M. Magdalita and being conducted at the Institute of Plant Breeding, Crop Science Cluster, College of Agriculture,
University of the Philippines Los Baños, College, Laguna. The project was approved by the National Biosafety Committee of the Philippines (NCBP) dated 28 December 1999. The screening for PRSV resistance and phenotypic characterization of $\mathrm{T}_{1}$ and $\mathrm{T}_{2}$ transgenic lines begun on 2004 and all experiments were terminated on 2006.

\section{Plant materials}

The yellow 'Solo' papaya was used in this study. Somatic embryos were induced from immature zygotic embryos isolated from immature green papaya. The somatic embryos were transformed via Agrobacterium-mediated transformation system using a binary vector containing the coat protein (CP) gene from a Philippine PRSV isolate to develop the $\mathrm{T}_{0}$ generation plants. The plant expression vector used contains an enhanced 35S promoter, a GMhsp 17.9 leader sequence from soybean, a $35 \mathrm{~S}$ 3'UTR, npt II selectable marker gene. The transformation work was conducted at the Malaysian Agricultural Research and Development Institute (MARDI) in Malaysia. Proliferating somatic embryos and calli were cocultivated with the activated bacterial culture $\left(\mathrm{OD}_{600}=0.2-0.5\right)$ for $2 \mathrm{~h}$ at $120 \mathrm{rpm}$ at $28^{\circ} \mathrm{C}$. After co-cultivation, the embryos were transferred to solid co-cultivation medium and incubated for 3 days. After this period, the embryo clusters were washed, blotted dry and incubated in somatic embryo induction medium plus carbenecillin $\left(500 \mathrm{mgl}^{-1}\right)$ for 2 weeks and subcultured in a selection medium with kanamycin $\left(150 \mathrm{mgl}^{-1}\right)$ until plantlets developed. The $\mathrm{T}_{0}$ plantlets in tissue culture were brought to the Philippines in January 2002 with permission from the Plant Quarantine Service-Bureau of Plant Industry (PQS-BPI). They were self-pollinated and grown to maturity to generate the $\mathrm{T}_{1}$ progeny lines.

Seedlings of the three selected $\mathrm{T}_{1}$ progeny lines were subjected to virus challenge and only seedlings that showed resistance were selected. The resistant $\mathrm{T}_{1}$ progeny plants from each of the three selected lines were transplanted in the BL2 greenhouse. The three selected transgenic lines namely: 124-3, 132-2 and 142-3 and the number of plants transplanted in soil in the BL2 greenhouse which were used as sources of progeny plants used in this study are shown in Table 1 . The three $\mathrm{T}_{1}$ lines came from the 11 lines that showed a Mendelian segregation for PRSV resistance.

\section{Screening for PRSV resistance}

Screening for PRSV resistance was done inside the BL2 greenhouse at IPB. Thirty to forty seedlings per transgenic line at the $T_{1}$ and $T_{2}$ generation and the non-transgenic control were raised. The seedlings were mechanically inoculated with the sap of PRSV-infected leaves by gently rubbing the virus inoculum onto the upper surface of the three uppermost expanded leaves previously dusted with carborundum. After inoculation, the leaves were rinsed briefly with distilled water. Three weeks after inoculation, the seedlings were assessed on a weekly basis for the presence or absence of the virus. Likewise, the symptom/s that developed on each test seedling was noted. The plants 
Table 1. The number of transgenic plants from $\mathrm{T}_{1}$ and $\mathrm{T}_{2}$ generation of selected resistant lines 124-3, 132-2 and 142-3 and the nontransgenic control plants transplanted in soil inside the BL2 greenhouse.

\begin{tabular}{ccc}
\hline \multirow{2}{*}{ Transgenic line } & \multicolumn{2}{c}{ Number of plants transplanted in soil } \\
\cline { 2 - 3 } & $\mathrm{T}_{1}$ & $\mathrm{~T}_{2}$ \\
\hline Control & 6 & 8 \\
$124-3$ & 16 & 7 \\
$132-2$ & 15 & 17 \\
$142-3$ & 12 & 3 \\
\hline
\end{tabular}

which appeared symptomless after two to three weeks from inoculation were re-inoculated to make sure that the resistance observed is not an escape from the virus. All inoculated and re-inoculated test seedlings were observed for their reaction to PRSV. A visual rating score of one (1) was given to test seedlings that showed PRSV symptoms, while a zero (0) score was given to the symptomless test seedlings. The visual rating for resistance of each test seedling was validated using the enzyme-linked immunosorbent assay (ELISA, Hull 2002, Nelson and Cox 2005). Each of the 30-40 test plants for each line, 2 leaf samples were used and each sample was replicated 2 times in the ELISA plate. All ELISA tests were repeated 2 times. Leaf sample was collected from the youngest fully expanded leaf of each test plant. The tissue was homogenized using mortar and pestle in $0.05 \mathrm{M}$ Carbonate Buffer, $\mathrm{pH} 9.6$ at $1: 10$ dilution. About $100 \mu \mathrm{l}$ of the sap was loaded onto each well of the ELISA microtiter plate. The plates were incubated at $4^{\circ} \mathrm{C}$ overnight and then washed 3 times at 5 min interval using a washing buffer $1 \times$ phosphate buffer saline (PBS) plus $0.05 \%$ Tween 20 , then $200 \mu \mathrm{l}$ of the freshly prepared blocking solution (PBS and BSA) was loaded onto each well, incubated under room temperature for $1 \mathrm{~h}$ and the plates were washed following the procedure described above. This was followed with the addition of $100 \mu \mathrm{l}$ of the captured antibody at 1:200 in the antibody buffer was loaded onto each well of the ELISA plate. Cross absorption was done by dissolving the capture antibody using antibody buffer to which sap from healthy papaya leaf was added at dilution of $1 \mathrm{~g}$ tissue per $30 \mathrm{ml}$ buffer. The plates were incubated at room temperature for $2-3 \mathrm{~h}$ and then washed following the procedures mentioned above. Then $100 \mu \mathrm{l}$ of the secondary antibody enzyme conjugate, Goat AntiRabbit Alkaline Phosphatase, at 1:1000 dilution was added to each well of the ELISA plate and then incubated at room temperature for 2-3h and the plates were washed. Each well was then loaded with $100 \mu \mathrm{l}$ of $p$-nitrophenyl phosphate substrate (PNP) (1PNP tablet per $5 \mathrm{ml}$ diethanolamine buffer $\mathrm{pH}$ 9.6) and incubated at room temperature. The wells were observed for the development of yellow color reaction indicating the presence of the virus in the sample and assessed based on the absorbance value measured in an ELISA plate reader.

The resistant transgenic seedlings were selected and transferred to soil placed in bigger plastic bags $(6 \times 8)$ and grown inside the BL2 greenhouse. The percent resistance was computed by dividing the number of resistant plants by the total number of inoculated plants, multiplied by $100 \%$.

The selected resistant plants from each line at the $\mathrm{T}_{1}$ and $\mathrm{T}_{2}$ generation were subsequently transplanted directly in soil inside the BL2 greenhouse extension under the supervision of the representatives from the regulatory agencies including the University of the Philippines Los Banos-Institutional Biosafety Committee (UPLB-IBC), Bureau of Plant Industry-Plant Quarantine Service (BPI- PQS) and the NCBP.

\section{Horticultural evaluation and line purification}

The selected resistant plants from each of the three $\mathrm{T}_{1}$ lines were transplanted directly in soil inside the BL2 extension greenhouse. Due to space limitations, only the best plants in each line were planted accordingly as follows: 16 from 25 resistant plants of $\mathrm{T}_{1}$ line 124-3, 15 from 19 resistant plants of $\mathrm{T}_{1}$ line 132-2, 12 from 17 resistant plants of $\mathrm{T}_{1}$ line 142-3 and six non-transgenic control plants but only two reached maturity.

Three months after transplanting directly in soil and when the first flower developed, phenotypic evaluation of each plant was done. Selected horticultural traits at flowering stage such as plant height, stem diameter, length of internodes and days to first flower were assessed. In addition, the ripe fruits were evaluated for selected fruit characters such as fruit weight, total soluble solids (TSS) and edible portion (EP). Evaluation of the selected characters was based on the descriptor criteria set for evaluating papaya by the International Board for Plant Genetic Resources (IBPGR 1988). The color of the stem, petiole, leaf, flower, fruit peel, flesh and seed was determined based from the Colour Chart of the Royal Horticultural Society (RHS) of London (RHS 1966).

The three selected transgenic lines $\left(\mathrm{T}_{0}\right)$ were either self- or sib-pollinated to produce the $\mathrm{T}_{1}$ and $\mathrm{T}_{2}$ generation progenies. Hermaphrodite flowers at the full-balloon stage produced by the transgenic lines were enclosed in glassine bags and were secured with a paper clip to allow self-pollination. The selfpollinated flowers were properly labeled. On the other hand, the female flowers were sib-pollinated artificially by pollens taken from a sibling hermaphrodite line and enclosed with glassine bag. The artificially pollinated flowers were monitored until fruits developed. The fruits that developed were properly labeled. The seeds extracted from self-pollination of $\mathrm{T}_{0}$ composed the $T_{1}$ lines while self-pollination of $T_{1}$ lines gave rise to the $\mathrm{T}_{2}$ progeny lines.

\section{Statistical analysis}

A standard Student $t$-test using the SAS program version 9.1 (SAS System 1985) was performed to determine any differences in the selected horticultural traits between the transgenic lines and the non-transgenic control both at the $\mathrm{T}_{1}$ and $\mathrm{T}_{2}$ generations. 
Table 2. Reaction to PRSV based on visual rating and ELISA reaction of inoculated seedlings of transgenic $\mathrm{T}_{1}$ lines 124-3, 132-2 and 142-3 and the non-transgenic control plants screened for PRSV resistance two months after mechanical inoculation.

\begin{tabular}{ccccc}
\hline Transgenic lines & No. of inoculated plants & Reaction to PRSV (R:S) & Resistant plants (\%) & ELISA reaction (-: +) \\
\hline Control & 10 & $0: 10$ & 0 & $0: 10$ \\
$124-3$ & 30 & $25: 5$ & 83 & $25: 5$ \\
$132-2$ & 27 & $19: 8$ & 70 & $19: 8$ \\
$142-3$ & 23 & $17: 6$ & 74 & $17: 6$ \\
\hline
\end{tabular}

\section{Results and discussion}

\section{Evaluation of $T_{1}$ generation}

Screening for PRSV resistance

Initially, $77 \mathrm{~T}_{1}$ lines were screened for PRSV resistance and showed varying reaction to PRSV. Eight weeks from inoculation, the test seedlings of the $T_{1}$ lines showed different reactions to the virus. Twenty-four $T_{1}$ lines were resistant to PRSV while the remaining 53 lines were susceptible. The resistance reaction of the lines as analyzed by Chi-square test showed that 11 out of $77 \mathrm{~T}_{1}$ lines showed a segregation pattern similar to Mendelian segregation ratio of 3:1 (Magdalita et al. 2004). Out of the $11 \mathrm{~T}_{1}$ lines almost having the Mendelian segregation, three lines including 124-3, 132-2 and 142-3 were selected.

The PRSV reaction and the pattern of segregation (resistant:susceptible) of test plants of the selected $\mathrm{T}_{1}$ lines 124-3, 132-2 and 142-3 two months after inoculation are presented in Table 2. While all three $\mathrm{T}_{1}$ lines showed relatively high resistance to PRSV, notably, $\mathrm{T}_{1}$ line 124-3 had the highest percentage of resistant plants of $83.0 \%$ out of 30 inoculated seedlings. The segregation of resistant to susceptible plants based on mechanical inoculation and ELISA tests of $\mathrm{T}_{1}$ line 1243 is very similar to $3: 1$ Mendelian segregation. This suggests that a single gene controls resistance in this line. However, since the results are preliminary, further evaluation of the transgene expression could be done in later generations. Conversely, $\mathrm{T}_{1}$ lines $142-3$ and 132-2 had only $74.0 \%$ and $70.0 \%$ resistant plants respectively based on both mechanical inoculation and ELISA tests. All non-transgenic control plants were susceptible. The occurrence of resistant plants in the $3 \mathrm{~T}_{1}$ lines and all susceptible plants in the non-transgenic control spells the difference between the transgenic and non-transgenic plants.

Symptoms of PRSV such as severe leaf deformation, mottling, mosaic, shoe-stringing, vein banding, chlorotic spots and water-soaked streaks on the stems of the inoculated non-transgenic control seedlings developed as early as two weeks post-inoculation. The PRSV symptoms on the susceptible $\mathrm{T}_{1}$ seedlings also developed two weeks post-inoculation same as in the control. The results of the ELISA obtained for each test plant for all three $T_{1}$ transgenic lines and non-transgenic
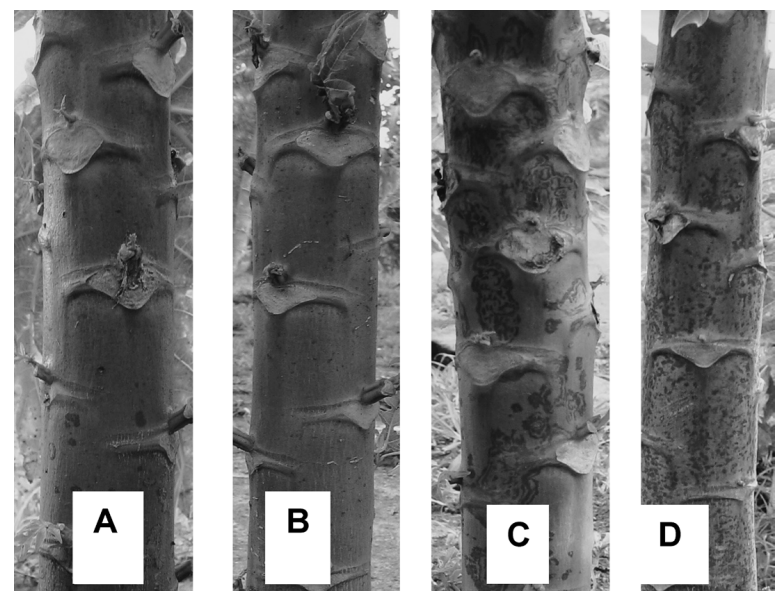

Figure 1. The light green (RHS $141 \mathrm{~B}$ ) stem color of the $\mathrm{T}_{1}$ transgenic line 132-2 (A), 124-3 (B) and 142-3 (C) is not different to the nontransgenic control (D).

control plants were consistent with the visual rating and confirmed the presence (or absence) of PRSV in the inoculated $\mathrm{T}_{1}$ seedlings.

\section{Horticultural evaluation}

The plants of $\mathrm{T}_{1}$ lines 124-3, 132-2 and 142-3 were morphologically similar to the non-transgenic control. Phenotypically, the $T_{1}$ transgenic lines have typical papaya characteristics similar to the non-transgenic control. Both the $T_{1}$ transgenic lines and the nontransgenic control had the same light green (RHS 141 B) stem color (Figure 1). Moreover, the leaf shape (palmate), leaf color (dark green, RHS $141 \mathrm{~A}$ ), number of main veins (7) and petiole length of the $T_{1}$ transgenic lines were also similar to the non-transgenic control (Figure 2 ), indicating that the transgenic are comparable to the non-transgenic. These observations corroborated with the results on evaluation of transgenic papaya in Thailand (Burns et al. 2003) and in Indonesia (Damayanti et al. 2005).

On the other hand, there was a difference between the transgenic $\mathrm{T}_{1}$ lines and the non-transgenic control in terms of plant height, and internode length (Table 3). Transgenic $T_{1}$ lines $124-3,132-2$ and 142-3 were significantly shorter than the non-transgenic control. The $\mathrm{T}_{0}$ plants from where these $\mathrm{T}_{1}$ lines were derived were short-statured, one of the criteria being considered in line selection and purification, hence the $T_{1}$ progenies 

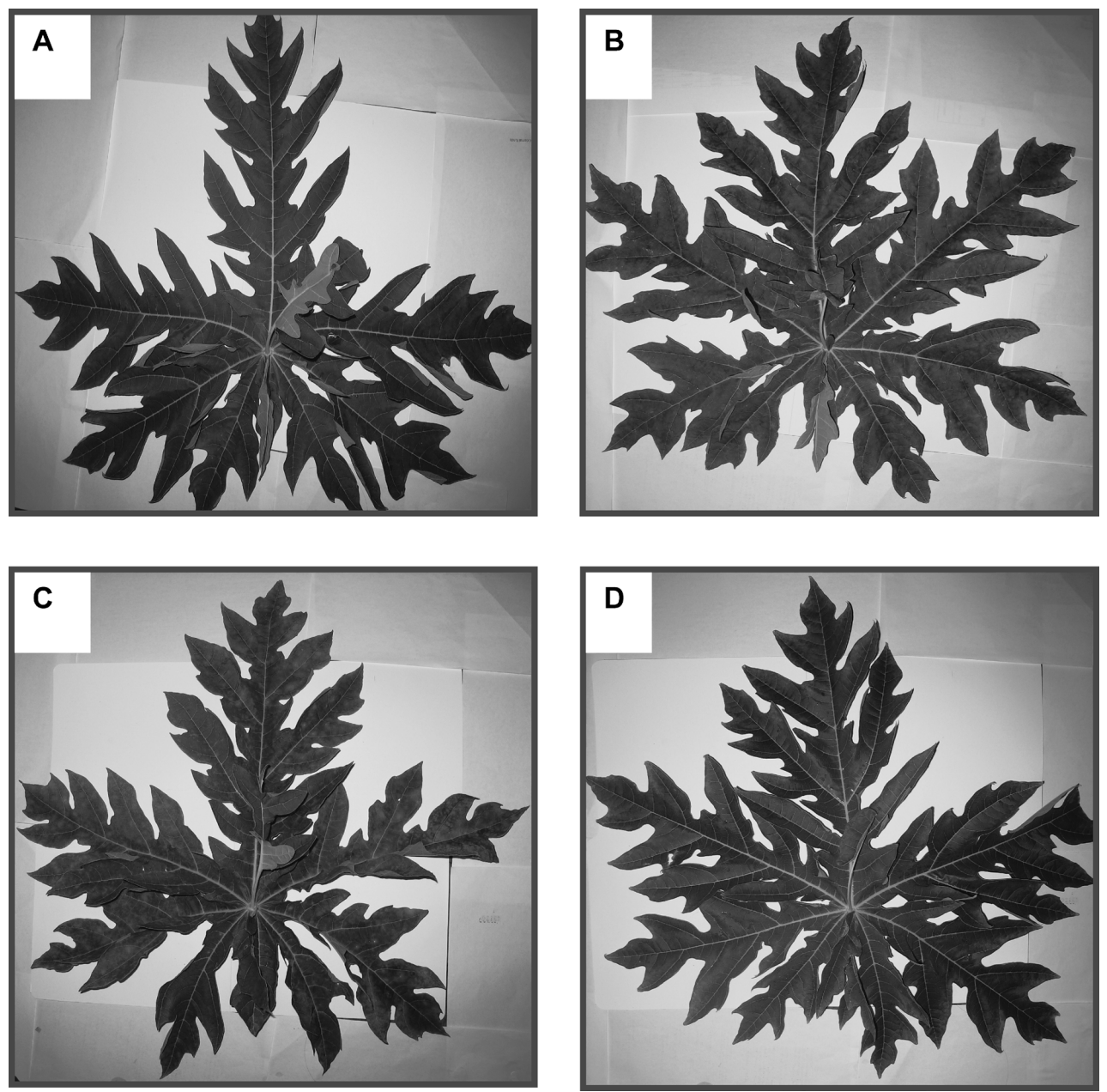

Figure 2. The palmate leaf shape, dark green (RHS $141 \mathrm{~A}$ ) leaf color and, number (7) of main veins of the transgenic $\mathrm{T}_{1}$ lines 124-3 (A), 132-2 (B) and 142-3 (C) are not different to the non-transgenic control (D).

were also short. This difference in height and internode length shows a difference between the transgenic and non-transgenic control. In the Philippines, papaya growers prefer relatively short-statured papaya plants than taller ones because of convenience in harvesting the fruits. Furthermore, being a country often visited by typhoons or tropical storms, shorter trees are preferred because taller ones are more prone to damage by strong winds.

The stem diameter of the $T_{1}$ transgenic lines was thinner than the non-transgenic control. In Malaysia, transgenic 'Eksotika' papayas had similarly thinner stem than the non-transgenic control (Ravindranathan et al. 2002).

In the present study, the $T_{1}$ transgenic lines had shorter internodes than the non-transgenic control. However, the $T_{1}$ lines 132-2 and 142-3 had significantly shorter internodes than the non-transgenic control and line 124-3. The internode length was directly correlated to the plant height of the transgenic and the non-transgenic control. In the case of the $T_{1}$ transgenic lines, their shorter internodes contributed to their plant

Table 3. Selected horticultural traits at flowering stage of the three transgenic $\mathrm{T}_{1}$ lines and the non-transgenic control.

\begin{tabular}{cccccc}
\hline \multirow{2}{*}{ Transgenic lines } & \multicolumn{4}{c}{ Horticultural traits $^{1}$} \\
\cline { 2 - 6 } & Plant height $(\mathrm{cm})$ & Stem diameter $(\mathrm{cm})$ & $\begin{array}{c}\text { Length of internodes } \\
(\mathrm{cm})\end{array}$ & $\begin{array}{c}\text { No. of days to first } \\
\text { flower }\end{array}$ & $\begin{array}{c}\text { No. of nodes to first } \\
\text { flower }\end{array}$ \\
\hline Control & 121.5 & 6.48 & 4.25 & 81 & 33 \\
$124-3$ & $86.3^{*}$ & 5.11 & 2.41 & 67 & 37 \\
$132-2$ & $86.1^{*}$ & 5.45 & $2.26^{*}$ & 64 & 35 \\
$142-3$ & $72.4^{*}$ & 5.24 & $2.08^{*}$ & 66 & 31 \\
\hline
\end{tabular}

${ }^{1}$ Mean values with asterisk $(*)$ are significantly different from the control at $5 \%$ level of significance by $t$-test. 

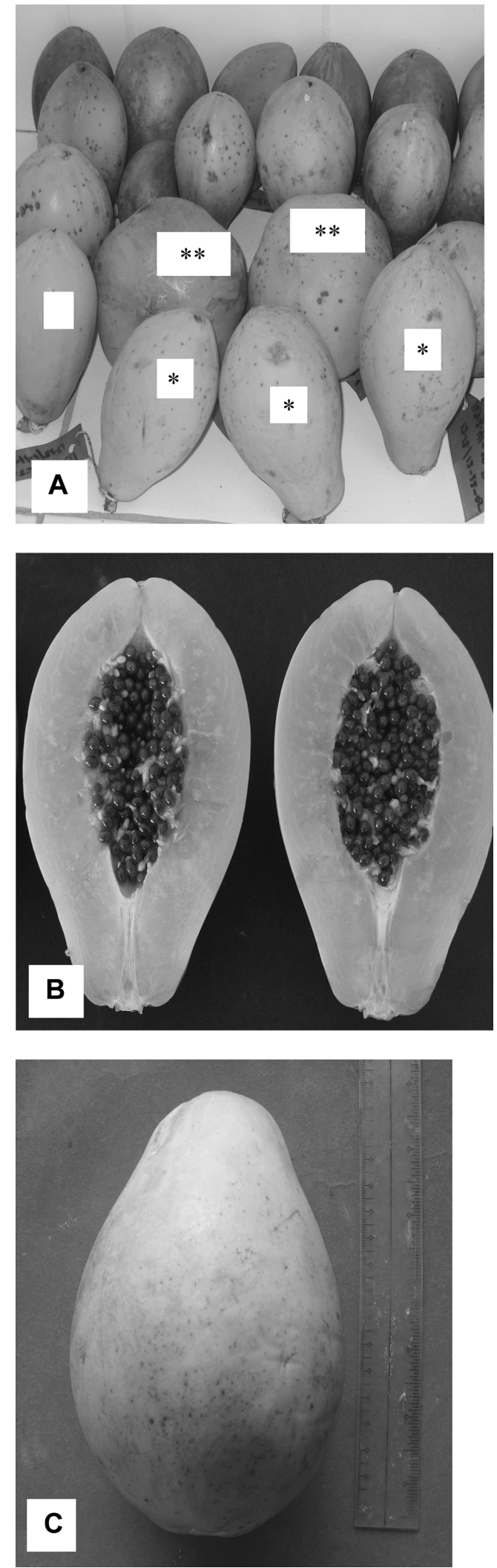

Figure 3. The hermaphrodite fruit form that is pyriform in shape* (female is rounded**), light yellow orange (RHS 17A) peel color (A), bright yellow orange (RHS 23A) flesh color and black (RHS 202A) seeds of the transgenic $T_{1}$ lines $(B)$ is not different to the hermaphrodite pyriform fruit shape (the female is rounded) of the non-transgenic control (C).
Table 4. Selected fruit characters evaluated in the three $\mathrm{T}_{1}$ transgenic lines and the non-transgenic control.

\begin{tabular}{|c|c|c|c|}
\hline \multirow{2}{*}{$\begin{array}{c}\text { Transgenic } \\
\text { lines }\end{array}$} & \multicolumn{3}{|c|}{ Fruit characters ${ }^{1}$} \\
\hline & $\begin{array}{l}\text { Fruit weight } \\
\text { (g) }\end{array}$ & $\begin{array}{l}\text { Total soluble } \\
\text { solids }\left({ }^{\circ} \mathrm{B}\right)\end{array}$ & $\begin{array}{c}\text { Edible portion } \\
(\%)\end{array}$ \\
\hline Control (3) & 567.3 & 12.2 & 75.3 \\
\hline $124-3(76)$ & 508.7 & $10.5^{*}$ & 71.5 \\
\hline $132-2(131)$ & $460.0^{*}$ & $10.4^{*}$ & 72.2 \\
\hline $142-3(62)$ & 483.7 & $10.0^{*}$ & 70.8 \\
\hline
\end{tabular}

${ }^{1}$ Mean values with asterisk (*) are significantly different from the control at $5 \%$ level of significance by $t$-test. Numbers in parenthesis ( ) refer to the total number of fruits evaluated in each line.

stature. It has been reported that internode length affects the plant height of 'Solo' papaya in Hawaii prior to flowering (Storey 1986).

The number of days to first flower of the $\mathrm{T}_{1}$ transgenic lines was not significantly different from the nontransgenic control. However, the three $T_{1}$ transgenic lines produced the first flower much earlier than the non-transgenic control. Probably, the transgenic lines are more genetically precocious than the non-transgenic control. A genetically determined number of nodes that developed following a short period of juvenility have been reported to induce flowering in 'Solo' papaya (Storey 1986). Precocious flowering in papaya is a desirable trait that promotes an earlier harvesting season for ripe fruits. Furthermore, the number of nodes to first flower of the three $T_{1}$ transgenic lines was also not significantly different with the non-transgenic control.

Generally, the fruit gross morphology, light yellow orange (RHS 17A) peel and bright yellow orange (RHS 23A) flesh color of the three transgenic lines are no different to the non-transgenic control phenotypically (Figure 3). Both the transgenic $\mathrm{T}_{1}$ lines and the nontransgenic control having hermaphrodite sex form, they borne bulb-shaped (pyriform) fruits, a typical shape of 'Solo' papaya. On the other hand, both the female transgenic lines and the non-transgenic control have rounded fruits. The two $T_{1}$ transgenic lines 124-3 and 142-3 had fruit weight not significantly different with the non-transgenic control. However, transgenic line 132-2 had fruit weight that is significantly different from the control.

All $\mathrm{T}_{1}$ transgenic lines had total soluble solids values that were significantly different from the non-transgenic control. Contrastingly, it has been reported that there is no significant difference in the fruits' total mass sucrose ( ${ }^{\circ}$ Brix) between transgenic and non-transgenic 'Khak Nual' papaya variety in Thailand (Chowpongpang et al. 2003).

Furthermore, there was no significant difference in the fruit's edible portion between the $T_{1}$ transgenic lines and the non-transgenic control, suggesting that they are not different from each other. The fruits of both the $T_{1}$ 
transgenic lines and the non-transgenic control have many black (RHS 202A) seeds, indicating that both of them are highly fertile, indicating that indeed the transgenic lines are not different to the non-transgenic control.

\section{Evaluation of $T_{2}$ generation}

Screening for PRSV resistance

Among the $\mathrm{T}_{2}$ plants that showed resistance to PRSV four months after inoculation under BL2 greenhouse conditions, six representative test plants of the three $\mathrm{T}_{2}$ transgenic lines ( 3 from 124-3, 2 from 132-2 and 1 from 142-3) that are free from PRSV symptoms were selected (Table 5). Based from the ELISA assay, the values obtained were similar to the negative control, but these values are several folds lower than the positive control. This result confirms the absence of the virus in the six symptomless transgenic $\mathrm{T}_{2}$ representative test plants. This may suggest inheritance of the transgene from the $T_{1}$ generation.

However, because there are susceptible test plants in the three $\mathrm{T}_{2}$ transgenic lines, this indicate instability of the resistance. Similar observation was made among transgenic papaya transformed with PRSV coat gene via microprojectile bombardment (Magdalita et al. 2011).

Expectedly, all the inoculated non-transgenic control test plants were susceptible to PRSV and had an ELISA value similar to the positive control and several folds higher than the negative control. The PRSV symptoms that developed on the susceptible $\mathrm{T}_{2}$ plants were similar to the symptoms of the inoculated control nontransgenic control.

\section{Horticultural evaluation}

The six selected resistant test plants in the three $T_{2}$ transgenic lines had gross morphological characteristics not different to the non-transgenic control (Table 6). The same observation was reported for transgenic papaya containing the PRSV coat protein gene that was developed in Thailand (Chowpongpang et al. 2003).

The plant height of the three $\mathrm{T}_{2}$ transgenic lines is significantly different from the non-transgenic control (Table 6). This observation was consistent with the result obtained in the $\mathrm{T}_{1}$ generation which is attributable to the selection for short statured progenies implemented in the $\mathrm{T}_{0}$ generation. In addition, the internode length of the three lines is significantly different from the nontransgenic control. Like the plant height, the intenode length of the transgenic lines is significantly shorter than the non-transgenic control. This shorter internode length is a function of the similarly shorter plant height. In addition, the number of nodes to first flower of the three transgenic $\mathrm{T}_{2}$ lines is significantly different from the non-transgenic control. The number of nodes to first flower of the transgenic $\mathrm{T}_{2}$ is significantly greater than the non-transgenic control. While the transgenic $\mathrm{T}_{2}$ lines have greater number of nodes to first flower, they are shorter than the non-transgenic control, hence the shorter plant height of the transgenic $\mathrm{T}_{2}$ lines. It has been reported that flowering in papaya is induced after

Table 5. Reaction to PRSV using mechanical inoculation and to ELISA of representative test plants of the three selected transgenic $\mathrm{T}_{2}$ lines and non-transgenic control four weeks after inoculation.

\begin{tabular}{|c|c|c|c|c|}
\hline \multirow{2}{*}{$\mathrm{T}_{2}$ transgenic line } & \multirow{2}{*}{ PRSV symptoms* } & \multirow{2}{*}{$\begin{array}{l}\text { ELISA reading for the test } \\
\text { plants }\left(\mathrm{OD}_{405}\right) *\end{array}$} & \multicolumn{2}{|c|}{ ELISA reading for the control $\left(\mathrm{OD}_{405}\right)$} \\
\hline & & & - & + \\
\hline $124-3.9-12.4$ & - & $0.191 \pm 0.05(-)$ & $0.174 \pm 0.07$ & $0.911 \pm 0.11$ \\
\hline $124-3.9-21.17$ & - & $0.109 \pm 0.08(-)$ & $0.174 \pm 0.09$ & $0.911 \pm 0.09$ \\
\hline $124-3.9-21.30$ & - & $0.131 \pm 0.04(-)$ & $0.174 \pm 0.12$ & $0.911 \pm 0.06$ \\
\hline $132-2.9-13.27$ & - & $0.236 \pm 0.06(-)$ & $0.230 \pm 0.13$ & $0.735 \pm 0.12$ \\
\hline $142-3.13-16.7$ & - & $0.222 \pm 0.13(-)$ & $0.230 \pm 0.07$ & $0.735 \pm 0.13$ \\
\hline Non-transgenic & + & $0.890 \pm 0.12(+)$ & $0.230 \pm 0.06$ & $0.735 \pm 0.12$ \\
\hline
\end{tabular}

* - indicates negative symptom of PRSV and negative reaction to ELISA.

Table 6. Selected horticultural traits of the three transgenic $\mathrm{T}_{2}$ lines and the non-transgenic control at flowering stage.

\begin{tabular}{|c|c|c|c|c|c|}
\hline \multirow[b]{2}{*}{ Transgenic lines } & \multicolumn{5}{|c|}{ Horticultural traits $^{1}$} \\
\hline & Plant height $(\mathrm{cm})$ & Stem diameter $(\mathrm{cm})$ & $\begin{array}{l}\text { Length of internodes } \\
\qquad(\mathrm{cm})\end{array}$ & $\begin{array}{c}\text { No. of days to first } \\
\text { flower }\end{array}$ & $\begin{array}{c}\text { No. of nodes to first } \\
\text { flower }\end{array}$ \\
\hline Control & 114.9 & 4.29 & 3.13 & 134 & 32 \\
\hline $124-3(7)$ & $81.3 *$ & 4.00 & $1.60 *$ & 142 & $47 *$ \\
\hline $132-2(17)$ & $78.0^{*}$ & 3.72 & $1.61^{*}$ & 115 & $39 *$ \\
\hline $142-3(3)$ & $76.8^{*}$ & 3.27 & $1.80 *$ & 126 & $53 *$ \\
\hline
\end{tabular}

${ }^{1}$ Mean values with asterisk $(*)$ are significantly different from the control at $5 \%$ level of significance by $t$-test. Numbers inside parenthesis ( ) represent the number of plants per line. 
a genetically determined number of nodes ranging from the 24th node from the ground level in a short statured variety and at the 48th node from the ground in a tall statured variety provided that the plants are growing under favorable environmental conditions (Storey 1986).

In contrast, the stem diameter of the transgenic $T_{2}$ lines is not significantly different with the non-transgenic control, suggesting that the transgenic $\mathrm{T}_{2}$ lines and the non-transgenic control are no different to each other in terms of stem diameter. Among the three $\mathrm{T}_{2}$ lines, line 124-3 had the stoutest stem diameter or girth of $4.00 \mathrm{~cm}$, while the transgenic $T_{2}$ line 142-3 had the thinnest stem diameter of $3.27 \mathrm{~cm}$. Likewise, the number of days to first flower of the transgenic $T_{2}$ lines is not different to the non-transgenic control. This result also suggests that the three transgenic $T_{2}$ lines are no different to the transgenic control, in terms of the number of days to first flower.

In terms of gross fruit morphology, fruit shape, light yellow orange (RHS 17A), peel color, and bright yellow-orange (RHS 23A) flesh color of ripe fruits of the transgenic $T_{2}$ lines and the non-transgenic control are the same, suggesting that the $\mathrm{T}_{2}$ transgenic lines and the non-transgenic control are indeed not different. However, the fruit weight of the $T_{2}$ transgenic lines was significantly different to the non-transgenic control plants (Table 7). In addition, the TSS and EP of the $T_{2}$ transgenic lines were significantly different to the nontransgenic control. While the fruit weight, TSS and EP of the three transgenic $\mathrm{T}_{2}$ lines are significantly different to the non-transgenic control, this does not imply that the transgenic lines are no longer equivalent to the nontransgenic control, because phenotypically the gross morphological characteristics of the plant and fruit are still falling within the characteristic range of the nontransgenic 'Solo' papaya.

\section{Comparison between $T_{1}$ and $T_{2}$ generations}

\section{Resistance to PRSV}

In both $\mathrm{T}_{1}$ and $\mathrm{T}_{2}$ generations, the selected plant progenies that were transplanted directly in soil were resistant to PRSV until the flowering stage but towards the end of the first fruiting cycle, they were infected. However, during the early screening stage for resistance to PRSV of the seedling progenies, the percentage of the PRSV resistant progenies differ in both $T_{1}$ and $T_{2}$ generations among the three transgenic lines.

In the $\mathrm{T}_{1}$ generation, line 124-3 had the highest percentage of resistance having $83 \%$ out of the 30 inoculated seedlings, $132-2$ had $70 \%$ out of the 27 inoculated seedlings and line $142-3$ had $74 \%$ out of the 23 inoculated seedlings (Table 8). However, the nontransgenic control had no resistance.

In comparison to the $\mathrm{T}_{1}$ generation, the $\mathrm{T}_{2}$ generation of the three transgenic lines had lower percentages of resistance than in $\mathrm{T}_{1}$ generation in all the three
$\mathrm{T}_{2}$ transgenic lines, possibly because coat protein accumulation could be lesser in the $\mathrm{T}_{2}$ generation than in the $\mathrm{T}_{1}$ generation, hence the coat protein offers a lesser degree of protection against the severe invading virus. This result indicates that the resistance of the three transgenic lines is unstable. In coat protein mediated protection against tobacco mosaic virus (TMV), it has been reported that the accumulation of coat protein in the transgenic tobacco plants is indispensable for protection against the virus and it appeared that the coat protein expressed in the transgenic plants interferes in the disassembly of the TMV particles, hence diminishing the protection rendered by the transgenic (Osbourn et. al. 1989; Register III and Beachy 1988).

In addition, the unstability of the resistance reaction observed in the three transgenic lines could be attributed to the segregation of the coat protein transgene, hence further evaluation of transgene expression could be done in later generations. It has been reported that the variation in the PRSV resistance of the $R_{2}$ seedling progenies of the transgenic KN49 papaya variety in Thailand's is due to the segregation of the coat protein transgene (Chowpongpang et al. 2005). Similarly, in Malaysia, it has been observed that the resistance is also unstable, as the number of resistant progenies (119) in the $\mathrm{R}_{0}$ (original transgenic plants) regeneration decreases to 13 in the $R_{1}$ generation and no resistant progenies were observed in the $\mathrm{R}_{2}$ generation (Habibuddin et al. 2007).

Table 7. Selected fruit characters at ripe stage of the transgenic $T_{2}$ lines and the non-transgenic control.

\begin{tabular}{cccc}
\hline \multirow{2}{*}{$\begin{array}{c}\text { Transgenic } \\
\text { lines }\end{array}$} & \multicolumn{3}{c}{ Fruit characters $^{1}$} \\
\cline { 2 - 4 } & $\begin{array}{c}\text { Fruit weight } \\
(\mathrm{g})\end{array}$ & TSS $\left({ }^{\circ} \mathrm{B}\right)$ & EP $(\%)$ \\
\hline Control (20) & 475.8 & 12.8 & 69.2 \\
$124-3(10)$ & $552.2^{*}$ & $10.5^{*}$ & $72.0^{*}$ \\
$132-2(57)$ & $587.8^{*}$ & $10.4^{*}$ & $71.9^{*}$ \\
$142-3(10)$ & $580.5^{*}$ & $10.3^{*}$ & $71.0^{*}$ \\
\hline
\end{tabular}

${ }^{1}$ Mean values with asterisk (*) are significantly different from the control at $5 \%$ level of significance by $t$-test. Numbers inside parenthesis ( ) represent the total number of fruits evaluated in each line.

Table 8. Percentage resistance to PRSV of the three transgenic lines in $T_{1}$ and $T_{2}$ generations. Reaction to PRSV of the test plants was assessed 60 days after inoculation.

\begin{tabular}{ccc}
\hline \multirow{2}{*}{ Transgenic lines } & \multicolumn{2}{c}{ Percent Resistance (\%) } \\
\cline { 2 - 3 } & $\mathrm{T}_{1}$ & $\mathrm{~T}_{2}$ \\
\hline $124-3$ & 83 & 41 \\
$132-2$ & 70 & 7 \\
$142-3$ & 74 & 8 \\
Control & 0 & 0 \\
\hline
\end{tabular}




\section{Horticultural evaluation}

The plant height of transgenic lines $124-3$ and 1423 in the $\mathrm{T}_{1}$ and $\mathrm{T}_{2}$ generation were not significantly different (Table 9). This result suggests that these two lines are stable in terms of plant height. The same trait in the $T_{1}$ and $T_{2}$ generations for transgenic line 132-2 was significantly different but it is still within the range of the height of 'Solo' papaya. In terms of internode length, there was no significant difference in the $\mathrm{T}_{1}$ and $\mathrm{T}_{2}$ generations for transgenic line 142-3, also suggesting stability of this transgenic line. On the other hand, the same trait for lines $124-3$ and $132-2$ in the two generations was significantly different, but the values for internode length still fall within the range of 'Solo' papaya.

On the overall, there is a fluctuation from $\mathrm{T}_{1}$ to $\mathrm{T}_{2}$ in terms of plant height (except for 142-3), stem diameter and length of internodes for all the 3 lines. This decrease may be due to the higher temperature $\left(30^{\circ} \mathrm{C}\right)$ that prevailed when the $\mathrm{T}_{2}$ are grown compared to the temperature $\left(28^{\circ} \mathrm{C}\right)$ when the $\mathrm{T}_{1}$ were grown, suggesting that less soil moisture is available for plant growth and development. In addition, rainfall is lesser during the growing season of the $\mathrm{T}_{2}(148.0 \mathrm{~mm})$ than during the growing season of the $\mathrm{T}_{1}(137.0 \mathrm{~mm})$. This further possibly explains why plant height, stem diameter and length of internode decreased.

In terms of number of nodes, there was no significant difference in the $\mathrm{T}_{1}$ and $\mathrm{T}_{2}$ generations for lines 132-2 and 142-3, but this trait was significantly different for line 124-3. However, in terms of stem diameter and number of days to flower, significant differences between the $T_{1}$ and $T_{2}$ generations for three transgenic lines were detected. It is interesting to note that generally, the number of days to flower of the three transgenic lines was much higher in the $\mathrm{T}_{2}$ where the plants were grown from August 2005 until March 2007, than in the $\mathrm{T}_{1}$ generation where the plants were grown from March 2004 to March 2005. Varying environmental conditions such as light duration, temperature and frequency of rainfall during the two different growing periods may have contributed to the difference in the number of days to flower by the three transgenic lines.

The qualitative traits at flowering stage such as light green (RHS 141B) stem color, dark green (RHS 141B) leaves and petiole, and creamy white (RHS 155A) flowers, are not different in both $\mathrm{T}_{1}$ and $\mathrm{T}_{2}$ generations for the three transgenic lines. Furthermore, a comparison of the selected fruit characters of the transgenic lines in the $\mathrm{T}_{1}$ and $\mathrm{T}_{2}$ generations was shown in Table 10. The fruit weight in the $T_{1}$ and $T_{2}$ generations of transgenic lines 124-3 and 142-3 was not significantly different, suggesting that these lines are relatively stable for fruit weight. However, in the same fruit character, for line 132-2, there is was a significant difference in the two generations. In terms of total soluble solids, there was no significant difference in the $\mathrm{T}_{1}$ and $\mathrm{T}_{2}$ generations among the three transgenic lines. In addition, there was no significant difference in terms of fruit edible portion of the $T_{1}$ and $T_{2}$ generations for three transgenic lines. The results suggest that edible portion and total soluble solids were stable for $\mathrm{T}_{1}$ and $\mathrm{T}_{2}$ generations for lines $124-3$ and 132-2.

Moreover, the fruit shape, light yellow orange (RHS

Table 9. Comparison of the selected horticultural traits at flowering stage of the three transgenic lines in the $\mathrm{T}_{1}$ and $\mathrm{T}_{2}$ generations.

\begin{tabular}{|c|c|c|c|c|c|c|}
\hline \multirow{3}{*}{ Horticultural traits ${ }^{1}$} & \multicolumn{6}{|c|}{ Transgenic line/Generation } \\
\hline & \multicolumn{2}{|c|}{$124-3$} & \multicolumn{2}{|c|}{$132-2$} & \multicolumn{2}{|c|}{$142-3$} \\
\hline & $\mathrm{T}_{1}$ & $\mathrm{~T}_{2}$ & $\mathrm{~T}_{1}$ & $\mathrm{~T}_{2}$ & $\mathrm{~T}_{1}$ & $\mathrm{~T}_{2}$ \\
\hline Plant height $(\mathrm{cm})$ & 86.3 & 81.3 & 86.7 & $78.0^{*}$ & 72.4 & 76.8 \\
\hline Stem diameter $(\mathrm{cm})$ & 5.11 & $4.00^{*}$ & 5.45 & $3.72 *$ & 5.24 & $3.27 *$ \\
\hline Length of internode $(\mathrm{cm})$ & 2.41 & $1.60^{*}$ & 2.26 & $1.60 *$ & 2.08 & 1.80 \\
\hline No. of days to first flower & 67 & $142 *$ & 64 & $115^{*}$ & 66 & $126^{*}$ \\
\hline No. of nodes to first flower & 37 & $47^{*}$ & 35 & 39 & 31 & 53 \\
\hline
\end{tabular}

${ }^{1}$ Mean values with asterisk $(*)$ are significantly different to $\mathrm{T}_{1}$ at $5 \%$ level of significance.

Table 10. Comparison of selected fruit characters at the ripe stage of the transgenic lines in the $\mathrm{T}_{1}$ and $\mathrm{T}_{2}$ generations.

\begin{tabular}{|c|c|c|c|c|c|c|}
\hline \multirow{3}{*}{ Fruit characters ${ }^{1}$} & \multicolumn{6}{|c|}{ Transgenic line/Generation } \\
\hline & \multicolumn{2}{|c|}{$124-3$} & \multicolumn{2}{|c|}{$132-2$} & \multicolumn{2}{|c|}{$142-3$} \\
\hline & $\mathrm{T}_{1}$ & $\mathrm{~T}_{2}$ & $\mathrm{~T}_{1}$ & $\mathrm{~T}_{2}$ & $\mathrm{~T}_{1}$ & $\mathrm{~T}_{2}$ \\
\hline Fruit weight (g) & 508.7 & 552.2 & 460.0 & $587.6^{*}$ & 509.0 & 515.8 \\
\hline TSS $\left({ }^{\circ}\right.$ Brix $)$ & 10.5 & 10.5 & 10.7 & 10.4 & 10.2 & 10.4 \\
\hline Edible portion (\%) & 71.5 & 72.0 & 72.2 & 71.9 & 72.8 & 72.0 \\
\hline
\end{tabular}

\footnotetext{
${ }^{1}$ Mean values with asterisk $(*)$ are significantly different to $\mathrm{T}_{1}$ at $5 \%$ level of significance using $t$-test.
} 
17A) peel and bright yellow-orange (RHS 23A) flesh color of the three transgenic lines were not different in the $T_{1}$ and $T_{2}$ generations. The fruit shape of the three transgenic lines was consistently pyriform or bulb-shape for the hermaphrodite form and rounded for the female form in both generations, which is typical of 'Solo' fruits. The fruits of the transgenic lines also consistently produced a lot of black (RHS 202A) seeds in both $T_{1}$ and $\mathrm{T}_{2}$ generations, indicating that they were fertile.

\section{Summary and conclusion}

A preliminary study aimed to determine the partial stability of the expression of resistance to PRSV and horticultural characters of transgenic lines previously transformed using the coat protein gene of the papaya ringspot virus by the Agrobacterium-mediated system was conducted under BL2 greenhouse conditions approved by the NCBP. Three selected transgenic lines namely: $124-3,132-2$ and $142-3$ in the $T_{1}$ and $T_{2}$ generations were assessed for resistance to PRSV using mechanical inoculation test and ELISA assay. Evaluation of the horticultural traits at flowering and ripe fruit stages was also done.

Based from preliminary results, the percentage of resistant seedling progenies in the $\mathrm{T}_{1}$ generation decreased in the $T_{2}$ generation, an indication that the inherited resistance of the three transgenic lines was unstable, hence further evaluation of the transgene expression could be done. In contrast, several horticultural traits of the transgenic lines were stable in both the $T_{1}$ and $T_{2}$ generations. Specifically, the light green (RHS 141B) stem color, dark green (RHS 141B) leaves and petiole, and creamy white (RHS 155A) flowers were stably expressed in the flowering stage by the three transgenic lines in both the $T_{1}$ and $T_{2}$ generations, indicating that these traits are seemingly stable and are comparable to the non-transgenic control. The plant height for lines 124-3 and 142-3, internode length for line 142-3 and number of nodes to first flower for lines 132-2 and 142-3 were also stable in both $\mathrm{T}_{1}$ and $\mathrm{T}_{2}$ generations.

Further, the qualitative ripe fruit characters such as the pyriform fruit shape for hermaphrodite sex form and rounded fruit shape for the female sex form, light yellow orange (RHS 17A) peel color, bright yellow-orange (RHS 23A) flesh color and black (RHS 202A) seeds of the three transgenic lines were stably expressed in both $T_{1}$ and $T_{2}$ generations. The fruit weight for lines 124-3 and 142-3 was stably expressed in both generations including the total soluble solids and fruit edible portion.

\section{Acknowledgments}

This study was part of a project, "Development and Commercialization of GM Papaya for Fresh Fruit and Papain
Production", implemented at the Crop Science Cluster-Institute of Plant Breeding, College of Agriculture, University of the Philippines Los Baños led by Dr. Pablito M. Magdalita. This project was funded by the Department of Science and TechnologyPhilippine Council for Agriculture, Aquatic, Forestry and Natural Resources Research and Development (DOST-PCAARRD) and supported by the International Service for the Acquisition of Agri-biotech Applications (ISAAA), Agricultural Biotechnology Support Project II (ABSP II) and Economic Modernization through Efficient Reforms and Governance (EMERGE). The authors acknowledged the contributions of Dr. Vermando M. Aquino, Ms. Lolita M. Dolores, Mr. Pierriden Perez, Mr. Marcelino T. Gregorio and Ms. Teresa de Leon. The suggestions of the anonymous reviewers were also acknowledged.

\section{References}

Accotto GP, Nervo G, Acciarri N, Tavella L, Vecchiati M, Schiavi M, Mason G, Vaira AM (2005) Field evaluation of tomato hybrids engineered with Tomato Spotted Wilt virus sequences for virus resistance, agronomic performance, and pollen-mediated transgene flow. Phytopathology 95: 800-807

Bau H-J, Cheng Y-H, Yu T-A, Yang J-S, Yeh S-D (2003) Broadspectrum resistance to different geographic strains of Papaya ringspot virus in coat protein gene transgenic papaya. Phytopathology 93: 112-120

Bau H-J, Cheng Y-H, Yu T-A, Yang J-S, Liou P-C, Hsiao C-H, Lin C-Y, Yeh S-D (2004) Field evaluation of transgenic papaya lines carrying the coat protein gene of Papaya Ringspot Virus in Taiwan. Plant Dis 88: 594-599

Bregitzer P, Tonks D (2003) Inheritance and expression of transgenes in barley. Crop Sci 43: 4-12

Burns P, Kumdee O, Bandee S (2003) Progress report of papaya delayed ripening project in Thailand for 2003. Unpublished country progress report presented at the Papaya Biotechnology Network of Southeast Asia Technical and Coordination Meeting held in Kamphaengsaen, Nakhom Pathom and Bangkok, Thailand, December 15-16, 2003

Chowpongpang S, Warin N, Bhunchotch A, Rodaree R, Pironrit N, Attathom S (2003) PRSV resistance and yield of transgenic papaya in the small scale field trial. Unpublished country progress report presented at the Papaya Biotechnology Network of Southeast Asia Technical and Coordination Meeting. Held in Kamphaengsaen, Nakhom Pathom and Bangkok, Thailand, December 15-16, 2003

Department of Agriculture-Bureau of Agricultural Statistics (2010) Crop production statistics of the Philippines. Diliman, Quezon City, 96

Damayanti D, Mariska I, Herman M (2005) Delayed ripening of papaya: current status and future activity in Indonesia. Unpublished country progress report presented at Papaya Biotechnology Network of Southeast Asia. Technical and Coordination Meeting held in the First World Hotel, Genting Highlands, Kuala Lumpur, Malaysia, November 20-21, 2005

Ferreira SA, Pitz KY, Manshardt R, Zee F, Fitch MMM, Gonsalves D (2002) Virus coat protein transgenic papaya provides practical control of Papaya Ringspot Virus in Hawaii. Plant Dis 86: 101-105

Fitch MMM, Manshardt RM, Gonsalves D, Slightom JL, Sanford JC (1992) Virus resistant papaya derived from tissues bombarded with the coat protein gene of Papaya Ringspot Virus. Bio/Tech 10: $1466-1472$ 
Fuchs M, Gonsalves D (2007) Safety of virus-resistant transgenic plants two decades after their introduction: lessons from realistic field risk assessment studies. Annu Rev Phytopathol 45: 173-202

Habibuddin H, Abubakar UK, Tan CS, Ong CA, Pillai V, NoorSuhana A (2007) Evaluation of the transgenic Eksotika papaya lines for resistance against the Papaya Ringspot Virus in Malaysia. Unpublished country progress report presented at Papaya Biotechnology Network of Southeast Asia Technical and Coordination Meeting held in Makati City and Los Baños, Laguna Philippines, June 14-15, 2007

Hull R (2002) Matthew's Plant Virology. 4th ed. Elsevier Academic Press, San Diego, California, USA. $1001 \mathrm{p}$

International Board for Plant Genetic Resources (IBPGR) (1988) Descriptors for Papaya. IBPGR, Rome, $33 \mathrm{p}$

Magdalita PM, Opina OS, Espino RRC, Villegas VN (1989) Epidemiology of Papaya Ringspot in the Philippines. Phil Phytopath 25: 1-11

Magdalita PM, Adkins SW, Godwin ID, Drew RA (1996) An improved embryo-rescue protocol for a Carica interspecific hybrid. Aust J Bot 44: 343-353

Magdalita PM, Parsley DM, Godwin ID, Drew RA, Adkins SW (1997) Screening Carica papaya $\times$ C. cauliflora hybrids for resistance to Papaya Ringspot Virus-type P. Plant Pathol 46: 837-841

Magdalita PM, Aquino VM, Dolores LM, Galvez HF (2004) Agrobacterium-mediated transformation of Philippine papaya for PRSV resistance. Unpublished terminal report May 1999 to April 2004 submitted to the Philippine Council for Agriculture, Forestry and Natural Resources Research and Development (PCARRD)

Magdalita PM, Valencia LD, Villegas VN (2011) Cloning of papaya ringspot virus coat protein gene and transformation of 'Solo' papaya through microprojectile bombardment. Philipp J Crop Sci 36: $45-56$

Nelson DL, Cox MM (2005) Lehninger Principles of Biochemistry. 4th ed. Prentice Hall, New Jersey, USA. 1119 p

Osbourn JK, Watts JW, Beachy RN, Wilson TAM (1989) Evidence that nucleocapsid disassembly and a later step in virus replication are inhibited in transgenic tobacco plants expressing the coat protein gene of Tobacco Mosaic Virus. Virol 158: $126-132$
Phironrit N, Chowpongpang S, Warin N, Bhunchoth A, Attathom S (2007) Small scale field testing of PRSV resistance in transgenic papaya line KN116/5. (Abstr). Acta Hortic : 740

Presting GG, Smith OP, Brown CR (1995) Resistance to Potato Leafroll Virus in potato plants transformed with the coat protein gene or with vector control constructs. Phytopathology 85: 469-442

Ravindranathan P, Muda P, Ying Kwok C, Abu Bakar UK, Pillai V, Peng Fatt L, Mat Daud H2002. Contained field evaluation of delayed ripening transgenic 'Eksotika' papaya. Unpublished country progress report presented at Papaya Biotechnology Network of Southeast Asia Technical and Coordination Meeting held in. Port Dickson, Malaysia, October 7-9, 2002

Register JC 3rd, Beachy RN (1988) Resistance to TMV in transgenic plants results from interference with an early event in infection. Virology 166: 524-532

Royal Horticultural Society (RHS) of London and Flower Council of Holland (1966) RHS Colour Chart. Leiden, Holland

Statistical Analysis System Institute, Inc. (1985) SAS/STAT Guide for personal computers. 6th ed. Cary, N.C.: SAS Institute, Inc. $378 \mathrm{p}$

Storey WB (1986) Carica papaya. In: Halvey AH, (ed.). CRC Handbook of Flowering Vol. 2, Boca Rotan, Florida: CRC Press, Inc. pp 147-154

Tennant P, Ahmad MH, Gonsalves D (2005) Field resistance of coat protein transgenic papaya to Papaya Ringspot Virus in Jamaica. Plant Dis 89: 841-847

Tricoli DM, Carney KJ, Russell PF, McMaster JR, Groff DW, Hadden KC, Himmel PT, Hubbard JP, Boeshore ML, Quemada HD (1995) Field evaluation of transgenic squash containing single or multiple virus coat protein gene constructs for resistance to Cucumber Mosaic Virus, Watermelon Mosaic Virus 2 and Zucchini Yellow Mosaic Virus. Bio/Tech 13: 1458-1465

Xu D, Collins GB, Hunt AG, Nielsen MT (1999) Agronomic performance of transgenic burley tobaccos expressing TVMV or AMV coat protein genes with and without virus challenges. Crop Sci 39: 1195-1202

Yang H, Ozias-Akins P, Culbreath AK, Gorbet DW, Weeks JR, Mandal B, Pappu HR (2004) Field evaluation of Tomato Spotted Wilt Virus resistance in transgenic peanut (Arachis hypogaea). Plant Dis 88: 259-264 